\title{
Effect of Aerobic Exercise on Fetal Outcomes in Diabetic Pregnant Women
}

\author{
FATIMA M. EL-BELIDY, M.Sc.*; ADLY A. SABBOUR, Ph.D.*; ABEER M. EL-DEEB, Ph.D.* and \\ AMIR A. GABR, M.D.** \\ The Department of Physical Therapy for Women's Health, Faculty of Physical Therapy* and \\ The Department of Medicine for Gynecology \& Obstetrics, Faculty of Medicine ${ }^{* *}$, Cairo University, Egypt
}

\begin{abstract}
Background: This study aimed to evaluate the effect of aerobic exercise on fetal outcomes including body weight, fetal length, head circumference, infants' chest circumference, abdominal circumference and Apgar score 1 and 2 in gestational diabetic women.
\end{abstract}

Material and Methods: Thirty gestational diabetic women were randomly distributed into two groups equal in number. The control group received insulin therapy and diet recommendations, while the exercise group received the same treatment and aerobic exercise in form of treadmill training for 30 minutes/day for 3 times/week.

Results: Comparing both groups post-intervention, results revealed that there were statistically non-significant differences in the gestational age $(p=0.48)$, infants' length $(p=0.86)$, head circumference $(p=0.15)$, infants' chest circumference $(p=0.09)$, and Apgar score $1(p=0.051)$. However, there was a statistical significant decrease in infants' weight $(p=0.003)$, and abdominal circumference $(p=0.001)$, as well as a statistical significant increase in Apgar score $2(p=0.02)$.

Conclusion: The aerobic exercise showed improvements in the fetal outcomes without producing any harmful effects to infants of diabetic women.

Key Words: Aerobic exercise - Fetal outcomes - Diabetic pregnant women.

\section{Introduction}

GESTATIONAL Diabetes Mellitus (GDM) is defined as a carbohydrate intolerance of varying degrees of severity with onset or first recognition during pregnancy. GDM is associated with an increased maternal risk for other pregnancy-related complications, such as pre-eclampsia, postpartum hemorrhage, and with an increased risk for developing type 2 diabetes after pregnancy [1]

Correspondence to: Dr. Fatima M. El-Belidy, The Department of Physical Therapy for Women's Health, Faculty of Physical Therapy, Cairo University, Egypt
Gestational diabetes mellitus puts the infants at risk, since GDM is associated with an increased risk for macrosomia, jaundice and birth trauma. Later in life, children of gestational diabetic mothers have an increased risk for obesity, abnormal glucose tolerance, and type 2 diabetes [2]

The common treatment for women with GDM is dietary advices and insulin treatment. Medical nutrition therapy remains the main strategy for the treatment of gestational diabetes [3]. Maintaining proper dietary intake is important for not only providing nutrients for maternal health and fetal growth but also maintaining proper blood glucose and ideal weight gain without ketonenemia [4] Although regular daily physical activity and/or exercise are an established therapeutic adjunct in type 2 diabetes in non-pregnant adults; it is not routinely offered to women with GDM. Pregnancy is a period in the life of women that is often associated with decreased daily physical activity and decreased participation in sports and exercise [5] This is because the physicians and mothers worry about several maternal physical responses during exercises that may be negatively affect the fetus [6].

In the absence of either medical or obstetric complications, the ACOG recommends 30 minutes or more of moderate exercise on most, if not all, days of the week for pregnant women [5]. Regular physical activity has been proven to result in marked benefits for mother and fetus. Maternal benefits include improved cardiovascular function, limited pregnancy weight gain, decreased musculoskeletal discomfort, reduced incidence of muscle cramps and lower limb oedema, mood stability, attenuation of GDM and gestational hypertension. 
Fetal benefits include decreased fat mass, improved stress tolerance, and advanced neurobehavioural maturation. Physical activity is accompanied with shorter labour and decreased incidence of operative delivery [7]

So, it was hypothesized that the aerobic exercise may be beneficial for fetus of diabetic pregnant women. Therefore, the aim of this study was to investigate the effect of aerobic exercises on fetal outcomes in diabetic pregnant women.

\section{Material and Methods}

Thirty pregnant women at 26 weeks' gestation participated in this study. They were selected from Kasr El-Aini Medical Hospitals. The participants were selected according to the following criteria: Pregnant women' age ranged from 20 to 35 years old and their Body Mass Index (BMI) were $>30 \mathrm{~kg} / \mathrm{m}^{2}$ and $<34.9 \mathrm{~kg} / \mathrm{m}^{2}$. They were diagnosed with GDM based on the International Association of Diabetes and Pregnancy Study Groups recommendations ( $2 \mathrm{~h}, 75 \mathrm{~g}$ Oral Glucose Tolerance Test (OGTT): Fasting glucose $\geq 92 \mathrm{mg} / \mathrm{dl}$ or a 1 -h result of $\geq 180 \mathrm{mg} / \mathrm{dl}$, or a $2-\mathrm{h}$ result of $\geq 153 \mathrm{mg} / \mathrm{dl}$ ) [4].

All women in both groups were given a full explanation of the study protocol before signing an informed consent form. This study was approved by the Research Ethical Committee, Faculty of Physical Therapy, Cairo University. Participants were randomly assigned into two groups as follows: Control group consisted of 15 pregnant diabetic women who received medical treatment in the form of insulin and dietary recommendations. Shortacting or rapid-acting insulin analogue was administered just prior to meals. The total daily dose was 0.7-1.0 units $/ \mathrm{kg}$, divided equally between NPHinsulin and prandial-insulin [8] . Exercise group consisted of 15 pregnant diabetic women. They received the same treatment as in the control group and engaged in a supervised aerobic exercise for 30 minutes, 3 days/week for 8 weeks. This study started from July 2014 till Dec. 2017.

\section{Anthropometric measures:}

Flexible, non-stretchable tape measurement was used to measure crown-heel length, head circumference, chest circumference and abdominal circumference of each infant in both groups within $48 \mathrm{~h}$ of delivery. Length was taken with infant supine, knees fully extended and soles of the feet held firmly against the foot board and head touching fixed board. Head circumference was measured by putting the tape anteriorly at glabella and posteriorly along with the most prominent point. Chest circumference was measured by placing the tape measurement at the level of xiphoid cartilage. All measurements were recorded to the nearest of $0.1 \mathrm{~cm}$ [9] . Electronic infant scale was used to measure infants' weights in both groups within $48 \mathrm{~h}$ of delivery. Doppler ultrasound machine was used to estimate the gestational age of each pregnant woman in both groups. This examination done for all pregnant women before starting the study by an obstetrician to estimate the gestational age (26 weeks' gestation) of each woman and to exclude cases of twins, placenta preavia, intrauterine growth retardation, as well as any fetal anomalies.

The Apgar score was assigned in the first few minutes after birth to determine infants that have difficulty breathing or have a problem that needs further care. Each infant was checked at one minute and five minutes after birth for heart and respiratory rates, muscle tone, reflexes, and color. Each area had a score of zero, one, or two, with 10 points as the maximum. A total score of 10 indicated that infant was in the best possible condition. If a baby has a difficult time during delivery, this lowered the Apgar score. Apgar scores of three or less indicated infants who needed immediate attention and care.

\section{Interventions:}

Treadmill machine (Treadmill Phantom AC2800, Taiwan) was used to apply aerobic exercise for pregnant women in the exercise group. Treadmill training consisted of warming up, active stage and cool down stages. Warming up stage consisted of 5 minutes treadmill walking at zero angle inclination at low speed. Active stage consisted of 20 minutes walking on a treadmill at a moderate intensity (score 13-14 on Borg scale for ratings of perceived exertion) at zero angle inclination with adjusting load to achieve $60 \%$ of her predictive age of maximal heart rate. Cooling down stage was in a form of pedaling at a speed of 60 revolutions per minute without load. The maximal heart rate was calculated according to the following equation: Maximal heart rate $=220$-age of the woman. Then, (60-70\%) of this maximal heart rate was calculated for each pregnant woman in this study, which was the moderate intensity of exercise involved during the active phase of her exercise session. The lower end of these ranges (60-70\% of maximal heart rate) appeared to be appropriate for the most pregnant women who did not engage in regular exercise before pregnancy. 


\section{Results}

\section{Demographic data:}

Table (1): General characteristics of pregnant women in both groups.

\begin{tabular}{lllll}
\hline Variable & Control group & Exercise group & $\begin{array}{c}t- \\
\text { value }\end{array}$ & $\begin{array}{c}p- \\
\text { value }\end{array}$ \\
\hline Age & $29.93 \pm 3.06$ & $31.00 \pm 3.18$ & -0.936 & $0.357 \mathrm{NS}$ \\
Weight & $75.9 \pm 3.69$ & $76.23 \pm 6.74$ & -0.168 & $0.868 \mathrm{NS}$ \\
Height & $155.27 \pm 3.13$ & $154.87 \pm 4.41$ & 0.287 & $0.776 \mathrm{NS}$ \\
BMI & $31.49 \pm 1.53$ & $31.72 \pm 1.22$ & -0.454 & $0.653 \mathrm{NS}$ \\
\hline
\end{tabular}

Data are expressed as mean $\pm \mathrm{SD}$.

NS : Not significant $=p>0.05$.

BMI: Body Mass Index.

The demographic data of the gestational diabetic pregnant women are shown in Table (1). None of these data showed significant differences between both groups pre-intervention $(p>0.05)$.

\section{Fetal outcomes:}

Table (2): Mean values of fetal outcomes in diabetic pregnant women post-intervention.

\begin{tabular}{|c|c|c|c|c|}
\hline Variable & $\begin{array}{l}\text { Control } \\
\text { group }\end{array}$ & $\begin{array}{l}\text { Exercise } \\
\text { group }\end{array}$ & $\begin{array}{c}t- \\
\text { value }\end{array}$ & $\begin{array}{c}p- \\
\text { value }\end{array}$ \\
\hline $\begin{array}{l}\text { - Gestational age } \\
\text { (weeks) }\end{array}$ & $37.93 \pm 1.10$ & $38.17 \pm 0.73$ & -0.705 & $0.48 \mathrm{NS}$ \\
\hline - Infant weight (kg) & $4.23 \pm 0.48$ & $3.69 \pm 0.44$ & 3.19 & $0.003 * *$ \\
\hline - Infant length $(\mathrm{cm})$ & $50.27 \pm 3.35$ & $50.03 \pm 3.99$ & 0.17 & $0.86 \mathrm{NS}$ \\
\hline $\begin{array}{l}\text { - Head circumference } \\
\quad(\mathrm{cm})\end{array}$ & $35.20 \pm 1.81$ & $34.40 \pm 1.14$ & 1.44 & $0.15 \mathrm{NS}$ \\
\hline $\begin{array}{l}\text { - Chest circumference } \\
(\mathrm{cm})\end{array}$ & $36.33 \pm 1.63$ & $35.00 \pm 2.51$ & 1.72 & $0.09 \mathrm{NS}$ \\
\hline $\begin{array}{l}\text { - Abdominal } \\
\text { circumference }(\mathrm{cm})\end{array}$ & $35.20 \pm 1.36$ & $33.53 \pm 1.13$ & 3.65 & $0.001 * *$ \\
\hline - Apgar score 1 & $6.13 \pm 1.73$ & $7.20 \pm 1.01$ & -2.06 & $0.051 \mathrm{NS}$ \\
\hline - Apgar score 2 & $7.60 \pm 1.45$ & $8.60 \pm 0.51$ & -2.515 & $0.02 *$ \\
\hline
\end{tabular}

Comparing both groups post-intervention, results revealed that there were statistically nonsignificant differences in the gestational age ( $p=$ $0.48)$, infants' length $(p=0.86)$, head circumference $(p=0.15)$, infants' chest circumference $(p=0.09)$, and Apgar score $1(p=0.051)$. However, there was a highly significant decrease in infants' weight $(p=0.003)$, and abdominal circumference $(p=0.001)$, as well as a statistical significant increase in Apgar score $2(p=0.02)$ in the exercise group.

\section{Discussion}

Gestational diabetes mellitus is associated with increased risk of developing macrosomia, which may lead to birth trauma. Also, it leads to an increased risk for developing obesity, abnormal glucose tolerance, and type 2 diabetes later in life.
Therefore, this study aimed to investigate the effect of aerobic exercise on fetal outcomes in gestational diabetic pregnant women. The present study showed non-significant difference in gestational age, infants' length, head circumference, infants' chest circumference, and Apgar score 1. However, there was a significant decrease in infants' weight and abdominal circumference, as well as a significant increase in Apgar score 2 in the exercise group.

The results are in agreement with Mette et al. [10] who indicated smaller babies in exercising women compared with non-exercisers, but the difference was small. Also, they reported that exercising women had a slightly decreased risk of having a child small for gestational age and large for gestational age. Also, these findings are in agreement with other studies, which concluded that exercise in working women is associated with smaller babies [11].

Another appealing finding in this study is that mean Apgar score 1 of the newborns showed no significant difference in the exercise group compared to the control group. Haakstad et al., [12] revealed that the Apgar score of the newborns was higher in the exercise group compared to the control group at 1-minute, but after 5-minutes, there was no difference.

Similarly, results from previous trials evaluating exercise during pregnancy and gestational age have showed no difference between exercise and control groups in mean of gestational age at delivery [13] Although several cohort studies suggest a reduction in the risk of preterm birth [14,15], we did not find differences between intervention and control groups. Also, Silva et al., [16] did not find statistically significant differences between groups in mean birth weight, length, and head circumference. No differences are found in birth length of babies exposed or not exposed to gestational exercise [17] Three of these studies met the current guidelines for exercise level $[\mathbf{1 8 , 1 9 ]}$. Nevertheless, the results of the present study confirm previous data, which showed that moderate intensity aerobic exercise does not negatively affect birth outcomes or gestational age. Reduced birth weight could be explained by the difference in neonatal fat mass.

Reduction in birth weight is explained that the birth weight may have been mediated by maternal weight gain; exercising women gained significantly less weight and weight gain was weakly related to birth weight. Another plausible mechanisms for reduced birth weight include decreased uterine blood flow during exercise, and decreased availa- 
bility of growth substrate. Abdominal circumference finding is explained by that continuation of a regular aerobic at or above a minimal training level during late pregnancy results in an asymmetric pattern of growth restriction that primarily impacts on neonatal fat mass. It had been reported that the exercise had no effect on offspring body composition with a proportional decrease in both lean and fat mass in exercise group compared with the control group [20].

\section{Conclusion:}

Aerobic exercise in the form of walking on a treadmill for 30 minutes, three times per week resulted in significant improvement in fetal outcomes without harmful effect to the fetus of the diabetic pregnant women.

\section{References}

1- DEMPSEY J., BUTLER C. SORENSEN T., LEE I., THOMPSON M. MILLER R. FREDERICK I. and WILLIAMS M.: A case-control study of maternal recreational physical activity and risk of gestational diabetes mellitus. Diabetes Res. Clin. Pract., 66 (2): 203-15, 2004.

2- FELL D., JOSEPH K., ARMSON B. and DODDS L.: The impact of pregnancy on physical activity level. Matern Child Health J., 25 (3): 120-3, 2001.

3- American Diabetes Association: Standards of medical care in diabetes. Role of Medical Nutrition Therapy in the management of gestational diabetesm. Diabetes Care, 38 (Suppl 1): S8-16, 2015.

4- METZGER B., BUCHANAN T., COUSTAN D., De LEIVA A., DUNGER D., HADDEN D., HOD M., KITZMILLER J., KJOS S., OATS J., PETTITT D., SACKS D. and ZOUPAS C.: Summary and recommendations of the Fifth International Workshop-Conference on Gestational Diabetes Mellitus. Diabetes Care, 30 Suppl (2): S251-60, 2007.

5- CATALANO P. and HAUGUEL-De S.: Is it time to revisit the pedersen hypothesis in the face of the obesity epidemic? Am. J. Obstet. Gynecol., 204 (6): 479-87, 2011.

6- BROWN W.: The benefits of physical activity during pregnancy. J. Sci. Med. Sport, 5 (1): 37-45, 2002.

7- KATARINA M., YVES S., MICHEL B. and BENGT K. Physical activity and pregnancy cardiovascular adaptations, recommendations and pregnancy outcomes. Sports Med., 40 (6): 493-507, 2010.

8- LANDON M. and GABBE S.: Gestational diabetes mellitus. Obstet. Gynecol., 118 (6): 1379-93, 2011.
9- TASKNAD A., BHAVANA L. and AJIT G.: Anthropometric measurements of term neonates in tertiary care hospital of Wardha district. A.J.M.S., 8 (2): 140-43, 2015

10- JUHL M., OLSEN J., ANDERSEN P.K., et al.: Physical exercise during pregnancy and fetal growth measures: A study within the Danish National Birth Cohort. Am. J. Obstet. Gynecol., 202: 63.e1-8, 2010.

11- MEGANN E., EVANS S., WEITZ B. and NEWNHAM J.: Antepartum, In-trapartum, and Neonatal Signifcance of Exercise on Healthy Low-Risk Pregnant Working Women. Obstet. Gynecol., 99 (3): 466-72, 2002.

12- HAAKSTAD L. and BO K.: Exercise in pregnant women and birth weight: A randomized controlled trial. B.M.C. Pregnancy Childbirth, 11: 66, 2011.

13- SILVA S., EVENSON K., RICARDO L. and HALLAL P.: Leisure-time physical activity in pregnancy and maternal-child health: A systematic review and meta-analysis of randomized controlled trials and cohort studies. Sports Med., 47 (2): 295-3 17, 2017.

14-HEGAARD H., HEDEGAARD M., DAMM P., OTTESEN B., PETERSSON K. and HENRIKSEN T.: Leisure time physical activity is associated with a reduced risk of preterm delivery. Am. J. Obstet. Gynecol., 198 (2): 180.e1180.e5, 2008

15- DOMINGUES M., BARROS A. and MATIJASEVICH A.: Leisure time physical activity during pregnancy and preterm birth in Brazil. Int. J. Gynaecol. Obstet., 103: 9$15,2008$.

16- SILVA S., HALLAL P., DOMINGUES M., BERTOLDI A., SILVEIRA M., BASSANI D. SILVA I., SILVA B., COLL C. and EVENSON: A randomized controlled trial of exercise during pregnancy on maternal and neonatal outcomes: Results from the PAMELA study. Int. J. Behav. Nutr. Phys. Act., 14: 175, 2017.

17- GIROUX I., INGLIS S., LANDER S., GERRIE S. and MOTTOLA M.: Dietary intake, weight gain, and birth outcomes of physically active pregnant women: A pilot study. Appl. Physiol. Nutr. Metab., 31 (5): 483-9, 2006.

18- JUHL M., OLSEN J., ANDERSEN P., NØHR E. and ANDERSEN A.: Physical exercise during pregnancy and fetal growth measures: A study within the Danish National Birth Cohort. Am. J. Obstet. Gynecol., 202 (1): 63.e1-8, 2010.

19- GIROUX I., INGLIS S., LANDER S., GERRIE S. and MOTTOLA M.: Dietary intake, weight gain, and birth outcomes of physically active pregnant women: A pilot study. Appl. Physiol. Nutr. Metab., 31 (5): 483-9, 2006.

20- SARAH A., HOPKINS JAMES C., BALDI WAYNE S., CUTFIELD L., McCOWAN L. and HOFMAN: Exercise training in pregnancy reduces Offspring size without changes in maternal insulin sensitivity. J. Clin. Endocrinol. Metab., 95 (5): 2080-8, 2010. 


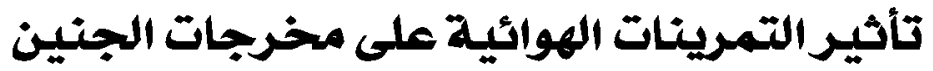

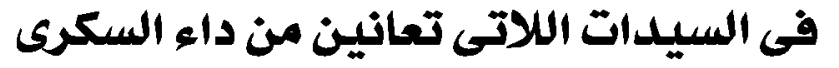

تهدف هذه الدراسة إلى تقييم تأثير التمرينات الهوائية على نتائج الجنين التى تحتوى على عمر الحمل وفنن وطول ومحيط الرأس والصدر

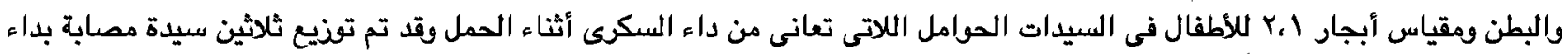

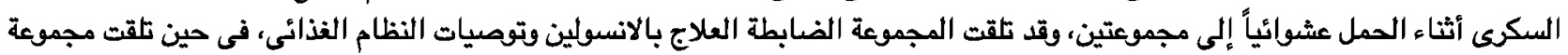

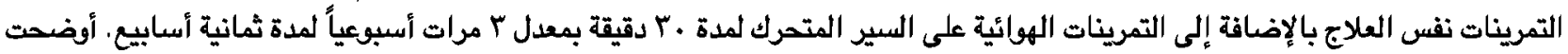

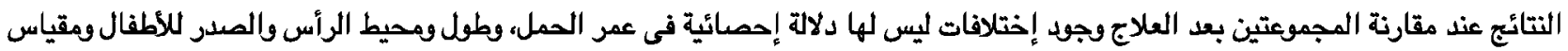

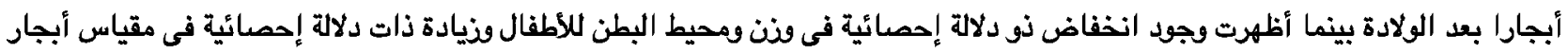

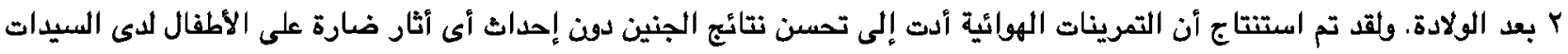

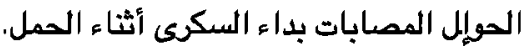

